\title{
PSYCHOLOGICAL CAPITAL DAN JOB RESOURCES SEBAGAI PREDIKTOR TERHADAP WORK ENGAGEMENT
}

\author{
Rifanji Reza Anatama \\ rranatama@yahoo.com \\ Fakultas Psikologi UIN Syarif Hidayatullah Jakarta
}

\begin{abstract}
This research aims to know the influence of self-efficacy, hope, optimism, resiliency, social support, relationship with supervisor, autonomy and performance feedback toward the work engagement. This research used 202 teachers as the sample. Sampling techniques that is used in this research is non-probability sampling. For measurement, this research used Confirmatory Factor Analysis (CFA). Data analysis that is used in this research is Multiple Regression Analysis in 0.05 significance level. The result of this research shows that there is a significant effect on self-efficacy, hope, optimism, resiliency, social support, relationship with supervisor, autonomy and performance feedback toward the work engagement. Meanwhile, hope, optimism, resiliency, social support, relationship with supervisor, autonomy and performance feedback do not have a significant effect towards the work engagement. The result of this research shows that variants proportion from work engagement that explained by all of the independent variable is $65.2 \%$, while the rest of $34.8 \%$ are affected by the other variables outside this research.
\end{abstract}

Keywords: psychological capital, job resources, work engagement

\begin{abstract}
Abstrak
Penelitian ini dilakukan untuk mengetahui pengaruh self-efficacy, hope, optimism, resiliency, social support, relationship with supervisor, autonomy dan performance feedback terhadap work engagement. Sampel dalam penelitian ini sebanyak 202 Guru. Teknik sampling yang digunakan dalam penelitian ini adalah non-probability sampling. Uji alat ukur menggunakan Confirmatory Factor Analysis (CFA). Analisis data yang digunakan dalam penelitian ini adalah Multiple Regression Analysis pada taraf signifikansi 0,05. Hasil penelitian menunjukkan bahwa ada pengaruh yang signifikan self-efficacy, hope, optimism, resiliency, social support, relationship with supervisor, autonomy dan performance feedback terhadap work engagement. Hasil uji hipotesis minor menunjukkan bahwa self-efficacy dan optimsm memiliki pengaruh yang signifikan terhadap work engagement. Sementara itu, hope, resiliency, social support, relationship with supervisor, autonomy dan performance feedback tidak memiliki pengaruh signifikan terhadap work engagement. Hasil penelitian juga menunjukkan proporsi varians dari work engagement yang dijelaskan
\end{abstract}


oleh seluruh variabel independen adalah $65,2 \%$, sedangkan $34,8 \%$ sisanya dipengaruhi oleh variabel lain di luar penelitian ini.

Kata kunci: psychological capital, job resources, work engagement

\section{PENDAHULUAN}

Munculnya pemahaman baru mengenai psikologi positif dapat meningkatkan kesadaran akan pentingnya kekuatan psikologi positif dalam menjelaskan fungsi manusia. Dengan kekuatan positif yang dimiliki, setiap individu memiliki potensi untuk menghasilkan produktivitas yang lebih baik untuk organisasinya. Salah satunya adalah totalitas kerja (work engagement).

Bakker (2010) menyatakan bahwa totalitas merefleksikan energi positif, menunjukkan antusiasme, hasrat yang nyata mengenai pekerjaan. Ketika individu terlibat secara aktif dalam pekerjaannya, mereka akan terdorong untuk berusaha maju dan menginginkan kesuksesan.

Berdasarkan Gallup Organization (Locke, 2003) menjelaskan bahwa pada tahun 2001 kurang dari 30\% pekerja di Amerika Serikat berdedikasi penuh pada pekerjaan, 55\% pekerja tidak terlibat, 19\% lainnya tidak aktif, artinya selain tidak bahagia dengan pekerjaan mereka dan menularkan perasaan itu kepada rekan-rekan kerja yang lain.

Selain itu, fenomena ini terlihat dari hasil observasi di Sekolah X pada Juni 2013, beberapa guru terlihat antusias dan segera masuk kelas untuk mengajar, ada juga guru yang terlihat masih mengobrol, makan snack ataupun sibuk dengan urusannya sendiri. Perbedaan terlihat ketika bel pulang berbunyi, terlihat banyak guru yang langsung bergegas untuk segera pulang. Hal ini yang menjadi masalah dalam totalitas guru pada Sekolah, karena kualitas Guru akan menentukan kualitas peserta didik di kemudian hari. Untuk itu, tanggung jawab dalam mengajar sangat perlu diperhatikan.

Faktor pertama yang mempengaruhi adalah modal psikologis (psychological capital). Psychological capital merupakan keadaan perkembangan psikologis seseorang yang terdiri dari karakteristik adanya kepercayaan diri, optimisme, harapan serta resiliensi yang merupakan kemampuan untuk betahan dan maju ketika dihadapkan pada sebuah masalah (Luthans, Youssef \& Avolio, 2007).

Avolio (2007) menjelaskan bahwa psychological capital dapat digunakan untuk meningkatkan kompetisi dalam mencapai kesuksesan organisasi dan akan mampu untuk terus berkembang. Individu tidak akan peduli dengan adanya perubahan maupun tantangan baru. Modal psikologis yang baik akan membuat seorang individu lebih menunjukkan peforma kerja yang optimal. Selain itu sebagai sumber daya yang penting bagi individu dapat mengatasi kelelahan kerja ataupun kondisi-kondisi yang 
menjenuhkan di tempat kerja, sehingga meminimalkan gejala-gejala stres dan akan selalu fokus pada pekerjaannya (Lazarus \& Folkman, 1984).

Selanjutnya, sumber daya pekerjaan (job resource) terkait dengan totalitas kerja dalam mencapai tujuan organisasi yang optimal. Karena dapat memainkan peran motivasi intrinsik dalam mendorong pertumbuhan individu, pembelajaran dan pengembangan atau melalui peran motivasi ekstrinsik yang membantu individu mencapai tujuan kerja sebelum seseorang memulai bekerja dan menunjukan kualitasnya (Schaufeli \& Bakker, 2004).

Modal psikologis dan sumber daya pekerjaan sangat diperlukan untuk membentuk suatu mental yang akan selalu dibawa ke dalam pekerjaan. Banyak hal yang akan membantu seseorang tersebut bila memiliki psikologis yang baik, salah satunya dapat terhindar dari kelelahan kerja (job burnout). Hal ini akan membantu seseorang untuk dapat memberikan kontribusi yang maksimal bagi organisasi.

Berdasarkan latar belakang tersebut, peneliti akan melakukan penelitian dengan judul "Psychological Capital dan Job Resources Sebagai Prediktor Terhadap Work Engagement."

\section{TEORI DAN HIPOTESIS}

Totalitas kerja (Work engagement) adalah perasaan atau sikap yang menunjukkan antusiasme, hasrat yang nyata mengenai pekerjaan, menikmati pekerjaan yang dilakukan dan berkeinginan untuk memberikan segala bantuan untuk dapat mensukseskan organisasi dimana individu tersebut bekerja. Lebih lanjut, menjelaskan bahwa seseorang yang memiliki work engagement yang tinggi akan bekerja keras, memberikan usaha yang lebih (extra effort) aktif terlibat, fokus terhadap pekerjaan, hadir secara fisik dan memberikan energi terhadap apa yang dikerjakan (Schaufeli et.al, 2004).

Menurut Schaufeli et, al. (2004), terdapat tiga dimensi dari work engagement, yaitu :

a). Vigor adalah curahan energi dan mental yang kuat selama bekerja, keberanian untuk berusaha sekuat tenaga dalam menyelesaikan suatu pekerjaan dan tekun dalam menghadapi kesulitan kerja.

b). Dedication adalah perasaan terlibat sangat kuat dalam suatu pekerjaan dan mengalami rasa kebermaknaan, antusiasme, kebanggaan, inspirasi dan tantangan dalam bekerja.

c). Absorption adalah perasaan larut dalam bekerja, selalu penuh konsentrasi dan serius terhadap suatu pekerjaan. Dalam bekerja waktu terasa berlalu begitu cepat dan menemukan kesulitan dalam memisahkan diri dengan pekerjaan. 
Modal psikologis (Psychological Capital) adalah kondisi perkembangan positif seseorang dan dikarakteristikan oleh:
a). Memiliki kepercayaan diri (self efficacy).
b). Membuat atribusi yang positif (optimism).
c). Tidak mudah menyerah dalam mencapai tujuan (hope).
d). Permasalahan dan halangan dapat bertahan dan kembali (resiliency).

Sumber daya pekerjaan (job resource) adalah aspek psikologis, sosial atau organisasi fisik pekerjaan yang baik untuk mengurangi tuntutan pekerjaan dan membantu untuk mencapai tujuan kerja. Bakker, Demerouti, \& Euwema (2005) mengkategorikan dimensi job resources menjadi empat variabel. Diantaranya:

a). Dukungan sosial (social support), dukungan dari rekan-rekan dapat membantu untuk menyelesaikan pekerjaan yang dilakukan pada waktunya.

b). Kualitas hubungan dengan supervisor, apresiasi dari pemimpin dan dukungan juga dapat membantu seseorang dalam bekerja, memfasilitasi kinerja, dan bertindak sebagai pelindung terhadap kesehatan yang buruk.

c). Otonomi (autonomy), hal ini dikaitkan dengan lebih banyak kesempatan untuk mengatasi situasi stres.

d). Umpan balik kinerja (performance feedback), tidak hanya membantu karyawan melakukan pekerjaan mereka lebih efektif, tetapi juga meningkatkan komunikasi antara supervisor dan karyawan lain.

\section{Hipotesis Penelitian}

\section{Hipotesis Mayor}

Ada pengaruh yang signifikan antara modal psikologis (psychological capital) dan sumber daya pekerjaan (job resources) terhadap (work engagement) pada guru Madrasah Tsanawiyah di Karawang?

\section{Hipotesis Minor}

$\mathrm{H}_{1} \quad$ : Ada pengaruh self-efficacy terhadap work engagement?

$\mathrm{H}_{2} \quad$ : Ada pengaruh hope terhadap work engagement?

$\mathrm{H}_{3} \quad$ : Ada pengaruh optimism terhadap work engagement?

$\mathrm{H}_{4} \quad$ : Ada pengaruh resiliency terhadap work engagement?

$\mathrm{H}_{5} \quad$ : Ada pengaruh social support terhadap work engagement?

$\mathrm{H}_{6} \quad$ : Ada pengaruh quality relationship with supervisor terhadap work engagement?

$\mathrm{H}_{7} \quad$ : Ada pengaruh autonomy terhadap work engagement?

$\mathrm{H}_{8} \quad$ : Ada pengaruh performance feedback terhadap work engagement? 


\section{METODE PENELITIAN}

\section{Pupulasi dan Sampel}

Pada penelitian ini yang dijadikan populasi adalah Guru Madrasah Tsanawiyah di Karawang. Pengambilan sampel pada penelitian ini menggunakan teknik non-probablity sampling yang berarti kemungkinan terpilihnya dari setiap responden anggota populasi tidak dapat dihitung. Peneliti menggunakan teknik non-probablity sampling dengan alasan tidak adanya data akurat yang diperoleh mengenai populasi. Peneliti menyebar sebanyak 230 kuesioner, tetapi hanya 202 yang kembali dan akan dijadikan sampel penelitian.

\section{Variabel penelitian}

Adapun variabel-variabel dalam penelitian ini, diantaranya:

1. Dependent variable : Work engagement

2. Independent variable : Psychological capital (self-efficacy, hope, optimism dan resiliency), job resources (social support, quality relationship with supervisor dan performance feedback).

\section{Instrument Pengumpulan Data}

Dalam penelitian ini peneliti mengunakan tiga skala, yaitu:

1. Utrect Work Engagement Scales (UWES) dari Schaufelli dan Bakker, 2003 terdiri dari 17 item.

2. Psychological Capital Questionnare (PCQ) dari Luthans \& Avolio, 2007 terdiri dari 24 item.

3. JD-R Model yang digunakan 14 item.

\section{Ujian Validitas Konstruk}

Untuk menguji keadaan instrumen yang digunakan pada penelitian ini, maka dilakukan uji validitas dengan menggunakan CFA (Confirmatory Factor Analysis). 


\section{Tabel 1}

Hasil Uji Validitas Konstruk

\begin{tabular}{|c|c|c|c|c|}
\hline Instrumen & Dimensi & No. Item & $\begin{array}{l}\text { No. Item } \\
\text { Tdk } \\
\text { Valid }\end{array}$ & $\begin{array}{l}\text { No. Item } \\
\text { Valid }\end{array}$ \\
\hline \multirow[b]{2}{*}{$\begin{array}{c}\text { Work } \\
\text { Engagement }\end{array}$} & Vigor & $1,2,3,4,5,6$ & - & $1,2,3,4,5,6$ \\
\hline & Dedication & $7,8,9,10,11$ & - & $7,8,9,10,11$ \\
\hline \multirow{4}{*}{ PsyCap } & Absorption & $\begin{array}{l}12,13,14,15 \\
16,17\end{array}$ & - & $\begin{array}{l}12,13,14,15 \\
16,17\end{array}$ \\
\hline & $\begin{array}{l}\text { Self-efficacy } \\
\text { Hope }\end{array}$ & & - & \\
\hline & Optimism & & - & \\
\hline & Resiliency & & - & \\
\hline \multirow[t]{4}{*}{$\begin{array}{c}\text { Job } \\
\text { Resources }\end{array}$} & $\begin{array}{l}\text { Social } \\
\text { Support }\end{array}$ & $1,2,3$ & - & $1,2,3$ \\
\hline & Supervisor & $4,5,6,7,8$ & - & $4,5,6,7,8$ \\
\hline & Autonomy & $9,10,11$ & - & $9,10,11$ \\
\hline & $\begin{array}{l}\text { Performance } \\
\text { Feedback }\end{array}$ & $12,13,14$ & - & $12,13,14$ \\
\hline Total & & 55 & 2 & 53 \\
\hline
\end{tabular}

Berdasarkan data pada tabel 1 menunjukan bahwa dari hasil uji konstruk yang dilakukan dari tiga alat ukur yang digunakan dalalam penelitian ini 2 item dinyatakan tidak valid $(t<1,96)$ dan 53 item lainnya valid $(t>1,96)$.

\section{Metode Analisis Data}

Analisis data adalah proses penelaahan data agar dapat ditafsirkan. Tujuan dari penafsiran tersebut adalah untuk memberikan makna pada data yang diperoleh dan menjelaskan pola atau kategori, kemudian mencari hubungan antara berbagai konsep. Pengolahan data dilakukan dengan analisa data secara statistik sebagai cara untuk mengetahui pengaruh variabel bebas psychological capital (self-efficacy, hope, optimism dan resiliency), job resources (social support, quality relationship with supervisor dan performance feedback) terhadap variabel terikat (dependent variable) yaitu work engagement.

Dalam rangka menjawab pertanyaan penelitian yaitu apakah terdapat pengaruh yang signifikan independent variable terhadap dependent variable, maka penulis menggunakan metode statistika, karena datanya berupa angka-angka yang merupakan hasil pengukuran atau perhitungan. 
Dalam hal ini hipotesis yang akan diukur, penulis menggunakan teknis analisis multiple regression atau analisis regresi berganda.

\section{HASIL PENELITIAN}

\section{Tabel 2}

\section{Tabel Anova Pengaruh Keseluruhan IV Terhadap DV}

\begin{tabular}{clccccc}
\hline \multicolumn{1}{c}{ Model } & & Sum of & & & & \\
\hline 1 & Squares & Df & Mean Square & F & Sig. \\
& Regression & 11914.518 & 8 & 1489.315 & 45.273 & $.000^{\mathrm{a}}$ \\
& Residual & 6348.950 & 193 & 32.896 & & \\
& Total & 18263.468 & 201 & & & \\
\hline
\end{tabular}

a. Predictors: (Constant), performance feedback, social support, autonomy, optimism, quality relationship, resiliency, self-efficacy, hope.

b. Dependent Variable: Work Engagement.

Berdasarkan data pada tabel 2 kolom ke 6 dari kiri diketahui bahwa $(\mathrm{p}<0.05)$ atau signifikan, maka hipotesis nol ditolak. Oleh karenanya hipotesis minor yang menyatakan ada pengaruh yang signifikan seluruh independent variable terhadap perilaku work engagament diterima. Artinya, ada pengaruh yang signifikan dari psychological capital (self-efficacy, hope, optimism dan resiliency), job resources (social support, quality relationship with supervisor dan performance feedback) terhadap work engagement.

Langkah terakhir adalah melihat koefisien regresi tiap independent variable. Jika nilai $\mathrm{t}>1,96$ maka koefisien regresi tersebut signifikan yang berarti bahwa IV tersebut memiliki dampak yang signifikan terhadap work engagement. Adapun penyajiannya ditampilkan pada table 3 berikut. 
Tabel 3

\section{Koefisien Regresi}

\begin{tabular}{|c|c|c|c|c|c|c|}
\hline \multirow[b]{2}{*}{ Mode } & & \multicolumn{2}{|c|}{$\begin{array}{l}\text { Unstandardized } \\
\text { Coefficients }\end{array}$} & \multirow{2}{*}{$\begin{array}{c}\begin{array}{c}\text { Standardized } \\
\text { Coefficients }\end{array} \\
\text { Beta }\end{array}$} & \multirow[b]{2}{*}{$\mathrm{T}$} & \multirow[b]{2}{*}{ Sig. } \\
\hline & & $\mathrm{B}$ & Std. Error & & & \\
\hline \multirow[t]{9}{*}{1} & (Constant) & -6.833 & 7.483 & & -.913 & .362 \\
\hline & Selfefficacy & .146 & .065 & .141 & 2.267 & .024 \\
\hline & Hope & .129 & .072 & .113 & 1.787 & .076 \\
\hline & Optimism & .669 & .066 & .597 & 10.189 & .000 \\
\hline & Resiliency & -.009 & .064 & -.008 & -.142 & .887 \\
\hline & Socialsupport & .080 & .043 & .084 & 1.854 & .065 \\
\hline & Qualityrelationship & .049 & .056 & .041 & .864 & .389 \\
\hline & Autonomy & .034 & .044 & .036 & .766 & .444 \\
\hline & Performancefeedback & .039 & .064 & .030 & .611 & .542 \\
\hline
\end{tabular}

a. Dependent Variable: Workengagement

Berdasarkan koefisien regresi pada table 3 dapat disampaikan persamaan regresi sebagai berikut:

$\mathrm{WE}=-6,833+0.141$ self-efficacy $+0,113$ hope $+0,597$ optimism -0.008 resiliency $+0,084$ social support $+0,041$ quality relationship $+0,036$ autonomy $+0,030$ performance feedback.

Berdasarkan data pada tabel 3, untuk melihat signifikan atau tidaknya koefisien regresi yang dihasilkan, kita cukup melihat nilai signifikan pada kolom yang paling kanan (kolom ke-6) jika $\mathrm{P}<0.05$, maka koefisien regresi yang dihasilkan signifikan pengaruhnya terhadap work engagement dan sebaliknya. Dari hasil di atas koefisien regresi dari self-efficacy dan optimism. dikatakan memiliki pengaruh yang signifikan sedangkan sisa lainnya tidak signifikan.

Hal ini berarti bahwa dari delapan independent variable hanya selfefficacy dan optimism yang signifikan. Penjelasan dari nilai koefisien regresi yang diperoleh pada masing-masing IV adalah sebagai berikut:

1. Variabel self-efficacy: diperoleh nilai koefisien regresi sebesar 0.141 dengan nilai $\mathrm{P}$-value sebesar $0,024(\mathrm{p}<0,05)$, yang berarti bahwa self-efficacy memiliki pengaruh yang signifikan terhadap work engagement. Dapat disimpulkan, semakin tinggi self-efficacy maka semakain tinggi work engagement.

2. Variabel hope: diperoleh nilai koefisien regresi sebesar 0,113 dengan nilai P-value sebesar 0,076 ( $p>0,05)$, yang berarti bahwa hope tidak memiliki pengaruh positif yang signifikan terhadap work engagement.

3. Variabel optimism: diperoleh nilai koefisien regresi sebesar 0,597 dengan P-value sebesar 0,000 ( $\mathrm{p}<0.05)$, yang berarti bahwa 
optimism memiliki pengaruh yang signifikan terhadap work engagement. Dapat disimpulkan, semakin tinggi optimism maka semakain tinggi work engagement.

4. Variabel resiliency: diperoleh nilai koefisien regresi sebesar $-0,008$ dengan P-value sebesar 0,887 ( $p>0,05)$, yang berarti bahwa resiliency tidak memiliki pengaruh yang signifikan terhadap work engagement.

5. Variabel social support: diperoleh nilai koefisien regresi sebesar 0,084 dengan P-value sebesar 0.065 ( $\mathrm{p}>0,05$ ), yang berarti bahwa social support tidak memiliki pengaruh positif yang signifikan terhadap work engagement.

6. Variabel quality relationship with supervisor: diperoleh nilai koefisien regresi sebesar 0,041 dengan $\mathrm{P}$-value sebesar 0,389 ( $\mathrm{p}>0,05)$, yang berarti bahwa quality relationship with supervisor tidak memiliki pengaruh yang signifikan terhadap work engagement.

7. Variabel autonomy: diperoleh nilai koefisien regresi sebesar 0,036 dengan P-value sebesar 0,444 ( $p>0,05)$, yang berarti bahwa autonomy tidak memiliki pengaruh positif yang signifikan terhadap work engagement.

8. Variabel performance feedback: diperoleh nilai koefisien regresi sebesar 0,030 dengan $\mathrm{P}$-value sebesar $0,542(\mathrm{p}>0,05)$, yang berarti bahwa performance feedback tidak memiliki pengaruh positif yang signifikan terhadap work engagement.

\section{Proporsi Varians}

Selanjutnya, peneliti ingin mengetahui bagaimana penambahan proporsi varians dari masing-masing independent variable terhadap work engagement. Pada tabel 4 kolom pertama adalah IV yang dianalisis secara satu per satu, kolom kedua merupakan penambahan varians DV dari tiap IV yang dianalisis satu per satu tersebut. Besarnya proporsi varians pada work engagement dapat dilihat pada tabel 4 .

\section{Keterangan:}

1. X1 : Self-efficacy

2. $\mathrm{X} 2:$ Hope

3. X3: Optimsim

4. X 4 : Resiliency

5. X5 : Social support

6. X6 : Quality relationship with supervisor

7. X7 : Autonomy

8. X8: Performance feedback 


\section{Tabel 4}

Proporsi Varians untuk Masing-Masing Independent Variable

\begin{tabular}{|c|c|c|c|c|c|c|c|c|c|}
\hline \multirow[b]{2}{*}{ Model } & \multirow[b]{2}{*}{$\mathrm{R}$} & \multirow[b]{2}{*}{$\begin{array}{c}\mathrm{R} \\
\text { Square }\end{array}$} & \multirow[b]{2}{*}{$\begin{array}{l}\text { Adjusted } \\
\text { R Square }\end{array}$} & \multirow[b]{2}{*}{$\begin{array}{l}\text { Std. Error } \\
\text { of the } \\
\text { Estimate }\end{array}$} & \multicolumn{5}{|c|}{ Change Statistics } \\
\hline & & & & & $\begin{array}{c}\mathrm{R} \\
\text { Square } \\
\text { Change }\end{array}$ & $\begin{array}{c}\mathrm{F} \\
\text { Change }\end{array}$ & df1 & $\mathrm{df2}$ & $\begin{array}{c}\text { Sig. F } \\
\text { Change }\end{array}$ \\
\hline 1 & $.575^{\mathrm{a}}$ & .330 & .327 & 7.82151 & .330 & 98.540 & 1 & 200 & .000 \\
\hline 2 & $.636^{\mathrm{b}}$ & .404 & .398 & 7.39371 & .074 & 24.813 & 1 & 199 & .000 \\
\hline 3 & $.800^{c}$ & .640 & .634 & 5.76508 & .235 & 129.316 & 1 & 198 & .000 \\
\hline 4 & $.800^{\mathrm{d}}$ & .640 & .633 & 5.77540 & .001 & .294 & 1 & 197 & .589 \\
\hline 5 & $.805^{\mathrm{e}}$ & .648 & .639 & 5.73001 & .007 & 4.133 & 1 & 196 & .043 \\
\hline 6 & $.807^{\mathrm{f}}$ & .651 & .640 & 5.72006 & .003 & 1.682 & 1 & 195 & .196 \\
\hline 7 & $.807^{\mathrm{g}}$ & .652 & .639 & 5.72624 & .001 & .579 & 1 & 194 & .447 \\
\hline 8 & $.808^{\mathrm{h}}$ & .652 & .638 & 5.73551 & .001 & .373 & 1 & 193 & .542 \\
\hline \multicolumn{10}{|c|}{$\begin{array}{l}\text { a. Predictors: (Constant), } \\
\text { SELFEFFICACY }\end{array}$} \\
\hline \multicolumn{10}{|c|}{ b. Predictors: (Constant), SELFEFFICACY, HOPE } \\
\hline \multicolumn{10}{|c|}{$\begin{array}{l}\text { c. Predictors: (Constant), SELFEFFICACY, HOPE, } \\
\text { OPTIMISM }\end{array}$} \\
\hline \multicolumn{10}{|c|}{$\begin{array}{l}\text { d. Predictors: (Constant), SELFEFFICACY, HOPE, OPTIMISM, } \\
\text { RESILIENCY }\end{array}$} \\
\hline \multicolumn{10}{|c|}{$\begin{array}{l}\text { e. Predictors: (Constant), SELFEFFICACY, HOPE, OPTIMISM, } \\
\text { RESILIENCY, SocialSupport }\end{array}$} \\
\hline \multicolumn{10}{|c|}{$\begin{array}{l}\text { f. Predictors: (Constant), SELFEFFICACY, HOPE, OPTIMISM, RESILIENCY, } \\
\text { SocialSupport, QualityRelationship }\end{array}$} \\
\hline \multicolumn{10}{|c|}{$\begin{array}{l}\text { g. Predictors: (Constant), SELFEFFICACY, HOPE, OPTIMISM, RESILIENCY, SocialSupport, } \\
\text { QualityRelationship, Autonomy }\end{array}$} \\
\hline
\end{tabular}

Kolom ketiga merupakan nilai murni varians DV dari tiap IV yang dimasukkan secara satu per satu, kolom keempat adalah nilai $\mathrm{F}$ hitung bagi IV yang bersangkutan, kolom DF adalah derajat bebas bagi IV yang bersangkutan pula, yang terdiri dari numerator dan denumerator, kolom $\mathrm{F}$ tabel adalah kolom mengenai nilai IV pada tabel $F$ dengan DF yang telah ditentukan sebelumnya, nilai kolom inilah yang akan dibandingkan dengan kolom nilai $\mathrm{F}$ hitung. Apabila nilai $\mathrm{F}$ hitung lebih besar daripada $\mathrm{F}$ tabel, maka kolom selanjutnya, yaitu kolom signifikansi yang akan dituliskan signifikan dan sebaliknya.

Berdasarkan data pada tabel 4.16 dapat disampaikan informasi sebagai berikut : 
1. Variabel self-efficacy memberikan sumbangan sebesar $33 \%$ dalam varians work engagement. Sumbangan tersebut signifikan dengan $\mathrm{F}$ Change $=98,540$ dan df $1=1$ dan $\mathrm{df} 2=200$ dengan Sig.F Change $=$ $0,000(\mathrm{p}<0,05)$.

2. Variabel hope memberikan sumbangan sebesar $7,4 \%$ dalam varians work engagement. Sumbangan tersebut signifikan dengan $F$ Change $=24,813$ dan $\mathrm{df} 1=1$ dan df2 $=199$ dengan Sig.F Change $=0,000(\mathrm{p}<0,05)$.

3. Variabel optimism memberikan sumbangan sebesar $23,5 \%$ dalam varians work engagement. Sumbangan tersebut tidak signifikan dengan $\mathrm{F}$ Change $=129,316$ dan df1 $=1$ dan df2 $=198$ dengan Sig.F Change $=$ $0,000(\mathrm{p}>0,05)$.

4. Variabel resiliency memberikan sumbangan sebesar $0,1 \%$ dalam varians work engagement. Sumbangan tersebut tidak signifikan dengan $\mathrm{F}$ Change $=0,294$ dan $\mathrm{df} 1=1 \mathrm{dan} \mathrm{df} 2=197$ dengan Sig. $\mathrm{F}$ Change $=0,589$ $(\mathrm{p}>0,05)$.

5. Variabel social support memberikan sumbangan sebesar $0,7 \%$ dalam varians work engagement. Sumbangan tersebut signifikan dengan $\mathrm{F}$ Change $=4,133$ dan df $1=1$ dan df2 $=196$ dengan Sig. $F$ Change $=0,043$ $(\mathrm{p}<0,05)$.

6. Variabel quality relationship with supervisor memberikan sumbangan sebesar $0,3 \%$ dalam varians work engagement. Sumbangan tersebut tidak signifikan dengan $\mathrm{F}$ Change $=1,682$ dan $\mathrm{df} 1=1$ dan $\mathrm{df} 2=195$ dengan Sig.F Change $=0,196(p>0,05)$.

7. Variabel autonomy memberikan sumbangan sebesar $0,1 \%$ dalam varians work engagement. Sumbangan tersebut signifikan dengan $\mathrm{F}$ Change= 0,579 dan df $1=1$ dan df2= 194 dengan Sig.F Change $=0,447(p<0,05)$.

8. Variabel performance feedback memberikan sumbangan sebesar $0,1 \%$ dalam varians work engagement. Sumbangan tersebut signifikan dengan $\mathrm{F}$ Change $=0,373$ dan $\mathrm{df} 1=1$ dan $\mathrm{df} 2=193$ dengan Sig. $\mathrm{F}$ Change $=$ $0,542(\mathrm{p}<0,05)$.

Dengan demikian, bahwa terdapat empat IV dari delapan IV, yaitu self-efficacy, hope, optimism dan social support yang mempengaruhi work engagement secara signifikan jika dilihat dari besarnya R2 yang dihasilkan dari sumbangan proporsi variabel yang diberikan. 


\section{KESIMPULAN DAN SARAN}

\section{Diskusi}

Hasil penelitian menunjukkan bahwa ada pengaruh yang signifikan variabel psychological capital (self-efficacy dan optimism) terhadap work engagemet pada Guru Madrasah Tsanawiyah di Karawang. Sedangkan variabel job resource menunjukkan tidak ada satu pun dimensi yang secara signifikan mempengaruhi work engagement pada Guru Madrasah Tsanawiyah di Karawang.

Schaufeli dan Bakker (2004) mendefinisikan totalitas kerja (work engagement) sebagai keadaan positif, afektif motivasional, pemenuhan hubungan kerja pada yang dikarakteristikkan dengan vigor, dedication dan absorption. Lebih lanjut, Schaufeli et.al, (2004) menjelaskan bahwa seseorang yang memiliki work engagement yang tinggi akan bekerja keras, memberikan usaha yang lebih (extra effort) aktif terlibat, fokus terhadap pekerjaan, hadir secara fisik dan memberikan energi terhadap apa yang dikerjakan.

Selanjutnya, Luthans (2007) menyatakan psychological capital sebagai kondisi perkembangan psikologis positif seseorang yang dikarakteristikan oleh: (1) memiliki kepercayaan diri (self efficacy) dalam mengambil menghadapi tugas-tugas yang menantang dan memberikan usaha yang cukup untuk sukses dalam tugas-tugas tersebut; (2) membuat atribusi yang positif (optimism) tentang kesuksesan di masa kini dan masa depan; (3) tidak mudah menyerah dalam mencapai tujuan dan bila perlu mengalihkan jalan untuk mencapai tujuan (hope); dan (4) ketika dihadapkan pada permasalahan dan halangan dapat bertahan dan kembali (resiliency), bahkan lebih, untuk mencapai kesuksesan.

Berdasarkan dalam hasil penelitian ini, variabel dari psychological capital yaitu self-efficacy memiliki pengaruh yang signifikan terhadap work engagement. Self-efficacy memiliki nilai koefisien regresi sebesar 0,141 dan signifikansi sebesar 0,024 ( $\mathrm{p}<0,05)$. Artinya, self-efficacy memiliki pengaruh yang signifikan terhadap work engagament.. Selanjutnya, optimism memiliki nilai koefisien regresi sebesar 0,597 dan signifikansi sebesar 0,000 ( $<<0,05)$. Artinya, optimism memiliki pengaruh yang signifikan terhadap work engagament. Dapat disimpulkan, semakin tinggi self-efficacy dan optimism maka semakin tinggi tingkat totalitas kerja (work engagement) pada Guru Madrasah Tsanawiyah di Karawang. Sedangkan dua variabel yang lain, yaitu hope dan resiliency tidak memiliki pengaruh yang signifikan terhadap work engagement.

Hal ini sejalan dengan penelitian yang dilakukan Luthans et.al, (2007) menemukan adanya pengaruh psychological capital terhadap work engagement karyawan. Avolio (2007) menjelaskan bahwa psychological capital dapat digunakan untuk meningkatkan kompetisi dalam mencapai 
kesuksesan organisasi dan akan mampu membuat individu untuk terus berkembang. Dapat disimpulkan bahwa semakin tinggi psychological capital maka akan semakin tinggi tingkat totalitas kerja (work engagement).

Berbeda dengan penelitian yang dilakukan Elisa Kurniadewi (2012) pada salah satu Kementrian X, menemukan bahwa psychological capital tidak memenuhi persyaratan signifikansi secara langsung terhadap employee engagement dengan nilai standardized sebesar 0,23 , dengan nilai $t=1,77$ yang lebih rendah dari nilai persyaratan $(t>1,96)$. Dengan demikian, psychological capital (self-efficacy, hope, optimism, resiliency) tidak terbukti memberikan pengaruh terhadap engagement secara signifikan.

Dalam penelitian ini, variabel job resources secara siginifikan tidak mempengaruhi work engagement. Dimensi yang pertama adalah social support dengan nilai koefisien regresi sebesar 0,084 dan $p$-value $0,065(\mathrm{p}<0,05)$ yang berarti bahwa social support tidak memiliki pengaruh yang signifikan terhadap work engagement. Hal ini sejalan dengan penelitian yang dilkakukan oleh C.F Coetzer \& S. Rothman yang menyatakan bahwa social support tidak signifikan dalam mempengaruhi work engagement. Berbeda dengan Halbesleben (dalam Bakker, 2010) menyatakan bahwa social support adalah salah satu prediktor yang penting terhadap work engagement.

Dimensi relationship with supervisor dengan nilai koefisien regresi sebesar 0,041 dan $p$-value $0,389(p<0,05)$ yang berarti bahwa relationship with supervisor tidak memiliki pengaruh yang signifikan terhadap work engagement. Hal ini tidak sejalan dengan penelitian yang dilakukan oleh Demerouti et.al, (2001) dan Hobfoll (2002) yang menemukan bahwa hubungan dengan atasan berhubungan positif dengan semangat, dedikasi dan penyerapan. Dari semua sumber daya pekerjaan yang diuji, menurutnya apresiasi dari atasan akan menjadi prediktor terkuat dari semua dimensi work engagement.

Dimensi autonomy dengan nilai koefisien regresi sebesar 0,036 dan $\mathrm{p}$-value $0,444(\mathrm{p}<0,05)$ yang berarti bahwa autonomy tidak memiliki pengaruh yang signifikan terhadap work engagement. Hal ini tidak sejalan dengan Mauno, Kinunuwen \& Ruokolainen (2007) penelitian longitudinal selama dua tahun menemukan hasil bahwa job resources merupakan prediktor work engagement dibandingkan job demands. Lebih lanjut, Halbesleben (2010) menyatakan autonomy adalah salah satu prediktor yang penting terhadap work engagement.

Dimensi performance feedback dengan nilai koefisien regresi sebesar 0,030 dan $p$-value $0,542(\mathrm{p}<0,05)$ yang berarti bahwa performance feedback tidak memiliki pengaruh yang signifikan terhadap work engagement. Hal ini tidak sejalan dengan Salanova dan Schaufeli (2008) yang menyatakan bahwa adanya hubungan positif anatara feedback dengan work engagement karena asumsi ini merujuk kepada hal yang sama, yaitu mendasari terbangunnya motivasi. Lebih lanjut, Halbesleben (2010) menyatakan 
performance feedback adalah salah satu prediktor yang penting terhadap work engagement.

Secara keseluruhan, peneliti berasumsi bahwa perbedaan dan ketidaksesuaian antara hasil penelitian terdahulu ini bisa diakibatkan oleh beberapa hal baik sampel, tempat penelitian, maupun alat ukur yang digunakan. Pihak sekolah tidak memberikan tuntutan kerja yang lebih untuk menyelesaikan setiap tugas yang diberikan. Yang terpenting adalah tanggung jawab secara profesional dalam memberikan pengajaran kepada para siswa-siswi dan menyelesaikan tugas-tugas tepat pada waktunya.

\section{Saran}

Berdasarkan penulisan penelitian ini, peneliti menyadari bahwa masih terdapat banyak kekurangan di dalamnya. Untuk itu, peneliti memberikan beberapa saran untuk bahan pertimbangan sebagai penyempurnaan penelitian selanjutnya, baik berupa saran teoritis dan saran praktis.

\section{Saran Teoritis}

1. Untuk penelitian selanjutnya, dapat menggunakan faktor-faktor lain yang menarik yang dapat dijadikan variabel independent untuk melihat pengaruhnya terhadap work engagement, seperti personal resources, job demands, leadership style dan job characteristic.

2. Untuk penelitian selanjutnya, disarankan untuk menggunakan alat ukur yang lain. Agar mendapatkan hasil yang berbeda/ bervariasi.

3. Untuk penelitian selanjutnya, gunakan sampel yang berbeda dengan jumlah yang lebih banyak. Sebaiknya sampel yang digunakan adalah subjek yang bekerja pada institusi/ perusahaan, karena tuntutan kerja yang lebih dan sumber daya pekerjaan yang berbeda akan menghasilkan hasil penelitian yang bervariasi.

\section{Saran Praktis}

1. Berdasarkan penelitian ini, diketahui bahwa self-efficacy dan optimism memiliki pengaruh yang signifikan terhadap totalitas kerja. Peneliti menyarankan kepada para guru untuk selalu memiliki keyakinan diri dan membentuk rasa optimis dalam menyelesaikan tugas-tugas ataupun pekerjaan, sehingga mampu mencapai tujuan pekerjaan dengan menunjukkan totalitas kerja.

2. Hasil penelitian ini dapat dijadikan bahan masukan yang positif bagi sekolah untuk lebih memperhatikan faktor-faktor yang dapat mempengaruhi totalitas kerja, khususnya modal psikologis dan sumber daya pekerjaan. Dengan memperhatikan modal psikologis setiap guru dan memberikan sumber daya pekerjaan yang baik, maka akan membentuk suatu mental yang akan dibawa ke dalam pekerjaan. Hal 
ini dapat membantu guru untuk memberikan kontribusi yang maksimal bagi organisasi.

3. Bagi para pimpinan sekolah maupun organisasi diharapkan juga untuk selalu menjaga hubungan dengan sesama rekan-rekan kerja yang terlibat, memberikan dukungan dan umpan balik kinerja satu sama lain, agar terus dapat meningkatkan kinerja untuk kemajuan organisasi itu sendiri. Salah satunya guru yang menjadi unsur penting di Sekolah dalam proses pembelajaran agar dapat memegang tanggung jawab, semangat dan selalu mendedikasikan diri dalam pekerjaannya yaitu mengajar dan memperhatikan perkembangan tiap siswa-siswi yang diajarnya.

\section{DAFTAR PUSTAKA}

Bakker, A.B. (2011). An evidence-based model of work engagement. Current Directions in Psychological Science, 20(4), 265-269.

Bakker, A.B., Leiter, M.P. (2010). Work engagement: A handbook of essential theory and research. New York: Psychology Press.

Bakker, A.B., Demerouti, E., \& Euwema, M.C. (2005). Job resources buffer the impact of job demands on burnout. Utrecht University: Journal of Organizational Health Psychology, 10(2), 170-180.

Bakker, A.B., Demerouti, E \& Schaufeli, W.B. (2009). Reciprocal relationship between job resources, personal resources and work engagement. Journal of Vacational Behavior, 74, 235-244.

Bakker, A.B. Schaufelli, W.B. Leiter, M.P. (2008). Work engagement: An emerging concept in occupational health psychology. Journal of Occupational Health Psychology, 22(3), 187-200.

Carolyn, M. Nicole, G. (2010). The role of personality in the job demands resources model a study of Australian academic staff. Journal of Development International 15(7), 1-15.

Demerouti, E., Bakker, A.B, Hakanen, J.J., Xanthopoulou, D. (2007). Job resources boost work engagement, particularly when job demands are high. Journal of Educational Psychology, 99(2), 274-284.

Coetzer, C.F., Rothmann, S. (2007). Job demands, job resources and work engagement of employees in a manucfaturing organization. South of Africa, 11(3), 20-35.

Halbesleben, J, R. A meta-analysis of work engagement: relationship with burnout, demands, resources and consequence. New York: Psychology Press.

Harrington, D. (2009). Confirmatory factor analysis. Oxford: University Press.

Hakanena, J.J, Schaufelli, W.B. The job demands-resources model: A three year crosslagged study of burnout, commitment and work engagement. Journal of Vocational Behavior, 22(3), 222-241. 
Hedissa, A.T. 2012. Hubungan psychological capital dengan kepuasan kerja pada anggota Polri yang sedang mengikuti pendidikan di Perguruan Tinggi Ilmu Kepolisian (PTIK). Universitas Indonesia, 1 (1), 1-8.

Jordaan, G.M, Rothmann, S. (2006). Job demands, job resources and work engagement of academic staff in South African higher education institutions. Journal of Industrial Psychology, 32 (4), 87-96.

Kurniadewi, Elisa. (2012). Psychological capital dan work-place well being sebagai prediktor terhadap employee engagement. Thesis: Fakultas Psikologi UIN Jakarta.

Luthans, F., Avey, J.B., \& Jensen, S.M. (2007). Psychological capital: A positive resource for combating employee stress and turnover. PersonalPsychology, 48(5), 677-693.

Luthans, F., Youssef, C. M., \& Avolio, Bruce. (2007). Psychological capital: developing the human competitive edge. New York: Oxford University Press.

Luthans, F., Avey, J. B., Avolio, B. J., \& Peterson, S. J. (2010). The development and resulting performance impact of positive psychological capital. Human Resource Development Quarterly, 21, 4167.

Mujiasih, E., Ratnaningsih, I, K. Increase work engagement through transformational leadership and organizational culture. Fakultas Psikologi UNDIP Semarang.

Pedhazur, F.J. (2007). Multiple regression in behavioral research: explanation and prediction. USA: Thompson Learning Inc.

Rothmann, S. Joubert, J.H.M. (2007). Job demands, job resources, burnout and work engagement of managers at a platinum mine in the North West Province. South of Africa: North West University, 38(3), 49-61.

Salanova, M, Schaufeli, W. B. (2008). A cross-national study of work engagement as a mediator between job resources and proactive behavior. Journal of Human Resource Management, 19(1), 116-131.

Schaufeli, Wilmar. (2011). Work engagement: what do we know?. Utrecht University The Neteherlands.

Schaufeli, W. B. \& Bakker., A.B. (2004). Job demands, job resources and their relationship with burnout and engagement: a multy sample study. Journal of Organizational Behavior, 25, 293-315.

Schaufe li, W. B. \& Bakker., A.B. (2003). Utrecht Work Engagement Scale (UWES). Utrecht University: Occupational Health Psychology Unit.

Schneider, B. (2008). The meaning of employee engagement. Journal Industrial and Organizational Psychology, 1, 3-30.

Sianturi, G.M. (2011). Psychological capital sebagai prediktor job insecurity. Universitas Sumatera Utara.

Walumbwa, Fred. Avey, J.B. (2011). Authentically leading groups: the mediating role of collective psychological capital and trust. Journal of Organizational Behavior. 32, 4-24. 
Xanthopoulou, D. \& Bakker, A.B. (2007). The role of personal resources in the job demands-resources model. $121-141$.

Xanthopoulou, D. Bakker, A.B. (2009) The crossover of daily work engagement: test of an actor-partner interdependence model. Journal of Applied Psychology, 94(6), 1562-1571.

Xanthopoulou, D. Demerouti, E. Schaufelli, W.B. (2009). Work engagement and financial returns: A diary Study on the role of job and personal resources. Journal of Occupational and Organizational Psychology, 82, 183-200. 
